\title{
KEEFEKTIFAN BUDAYA LITERASI DI SD N 3 BANJAR JAWA UNTUK MENINGKATKAN MINAT BACA
}

\author{
Ade Asih Susiari Tantri ${ }^{1},{ }^{*}$, I Putu Mas Dewantara² \\ 1 Universitas Pendidikan Ganesha \\ 2 Universitas Pendidikan Ganesha
}

\begin{abstract}
Abstrak
Penelitian ini merupakan penelitian deskriptif kualitatif yang bertujuan untuk mengetahui sejauh mana keefektifan budaya literasi di SD N 3 Banjar Jawa untuk meningkatkan minat baca siswa. Metode pengumpulan data yang digunakan dalam penelitian ini meliputi: wawancara, observasi, angket, dan kuisioner. Teknik analisis data yang digunakan dalam penelitian ini adalah model Miles dan Huberman, yaitu: reduksi, sajian data, dan penarikan simpulan. Dari hasil penelitian terjadi peningkatan persentase minat baca siswa dari 48\% di tahun 2016 menjadi $75 \%$ di tahun 2017 . Program budaya literasi yang dikemas dengan: kegiatan 15 menit membaca sebelum jam pelajaran; menata perpustakaan sekolah dan perpustakaan mini di kelas; menciptakan lingkungan yang kaya teks; membuat pojok baca; dan melaksanakan sabtu literasi efektif untuk meningkatkan minat baca siswa.
\end{abstract}

Keywords:

budaya literasi, minat

baca, dan SDN 3

Banjar Jawa

\section{PENDAHULUAN}

Membaca adalah kegiatan wajib bagi siswa. Siswa yang gemar membaca akan memiliki wawasan dan pengetahuan yang luas. Oleh karena itu, siswa harus memiliki minat baca yang tinggi agar mampu mengikuti perkembangan IPTEKS (Rahim, 2011). Selain itu, siswa yang rajin membaca akan memiliki kemampuan berpikir kritis. Yunus juga menyatakan bahwa membaca merupakan kunci keberhasilan seorang siswa. Hal ini sudah jelas manfaat membaca untuk keberhasilan siswa di masa depan (Sudiana, 2007).

Sudah sangat jelas pentingnya membaca untuk keberhasilan siswa, namun, dari beberapa survey membuktikan bahwa minat baca masyarakat Indonesia masih rendah. Berdasarkan studi "Most Littered Nation In the World" yang dilakukan oleh Central Connecticut State Univesity pada Maret 2016 lalu, Indonesia dinyatakan menduduki peringkat ke-60 dari 61 negara soal minat membaca. Padahal, dari segi penilaian infrastuktur untuk mendukung membaca peringkat Indonesia berada di atas negara-negara Eropa (Kompas, 2016).

Maka dari itu, perlu adanya terobosan dari segala pihak, khususnya pihak sekolah untuk meningkatkan minat baca siswa. Program yang paling tepat adalah dengan membudayakan literasi di lingkungan sekolah. Sekolah dasar adalah sekolah yang paling tepat untuk membudayakan literasi karena budaya literasi harus diterapkan sedini mungkin. Menurut Rahma "minat baca harus ditanamkan sejak dini agar seseorang akrab dengan buku sedini mungkin(Rahma, Pratiwi, \& Lastiti, 2015)." Jika sudah terbiasa membaca sejak dini, maka di jejang berikutnya siswa akan lebih haus untuk membaca.

Salah satu sekolah dasar yang sangat peduli dengan masalah ini adalah SD N 3 Banjar Jawa. Minat baca siswa SD N 3 Banjar Jawa dipantau masih rendah. Dari hasil angket di tahun 2016, persentase ratarata minat baca siswa, yaitu 48\%. Maka dari itu, kepala SD N 3 Banjar Jawa membuat program budaya literasi. Dari pantauan guru dan kepala sekolah, minat baca siswa semakin meningkat dengan adanya program ini, tetapi sejauh apa belum terukur dengan baik. Maka dari itu, perlu diteliti mengenai: program-program apa saja yang dilakukan untuk mendukung program budaya literasi di SD N 3 Banjar Jawa; kendala yang dihadapi serta solusi yang bisa ditawarkan; dan seberapa persen keefektifan budaya literasi di SD N 3 Banjar Jawa untuk meningkatkan minat baca siswa. Dengan terukurnya keefektifan budaya literasi di SD N 3 Banjar, sekolah dasar lainnya di Buleleng dapat mengembangkan program budaya literasi yang sama dan lebih baik lagi untuk membantu program Gerakan Literasi Sekolah (GLS) yang digagas pemerintah untuk meningkatkan minat baca siswa. 


\section{METODE PENELITIAN}

Penelitian ini menggunakan pendekatan deskriptif kualitatif. Pendekatan deskriptif kualitatif memaparkan dan membahas sesuai kenyataan di lapangan mengenai program budaya literasi dan keefektifannya untuk meningkatkan minat baca siswa SD N 3 Banjar Jawa.

Data penelitian ini berupa pandangan, pendapat, dan tindakan yang berkaitan dengan keefektifan program budaya literasi di SD N 3 Banjar Jawa untuk meningkatkan minat baca siswa. Data ini dikumpulkan dengan teknik observasi non partisipan, wawancara tak terstruktur, angket tertutup, dan kuisioner terbuka.

Teknik pemeriksaan keabsahan data yang dilakukan yaitu dengan triangulasi data, yaitu triangulasi sumber, triangulasi metode, dan review informan. Sedangkan teknik analisis data yang digunakan untuk menganalisis data yang telah dikumpulkan, yaitu teknik analisis model Miles dan Model Huberman (Moleong, 2013). Model ini meliputi tiga komponen utama, yaitu: reduksi data, sajian data, dan penarikan simpulan

\section{ANALISIS DAN PEMBAHASAN}

Program-program yang dijalankan untuk mendukung budaya literasi di SD N 3 Banjar Jawa, yaitu sebagai berikut. Pertama, kegiatan 15 menit membaca sebelum jam pelajaran. Dari hasil angket yang diberikan kepada wali kelas 1-6, wali kelas mendapingi siswa saat membaca. Supaya siswa tidak jenuh, wali kelas bersama-sama siswa membaca buku cerita. Wali kelas membacakan anak-anak cerita terutama di kelas rendah, yaitu kelas 1 dan 2 . Wali kelas setiap awal atau akhir kegiatan selalu memotivasi siswa untuk terus membaca dan mejelaskan akan besarnya manfaat membaca.

Kedua, menata perpustakaan sekolah dan perpustakaan mini di kelas. Di perpustakaan SD N 3 Banjar Jawa, buku-buku ditata dengan rapi di rak yang menempel di dinding. Buku-buku penting dimasukkan ke rak kaca. Piala-piala yang diraih oleh siswa-siswinya baik itu ditingkat lokal, provinsi, dan nasional ditata rapi di atas almari buku. Hal ini ditujukan agar siswa-siswi yang berkunjung ke perpustakaan termotivasi untuk selalu berprestasi di bidang akademik dan nonakademik. Tempat membaca dibuat lesehan agar siswa-siswinya merasa nyaman membaca dan merasa sedang membaca di rumah masing-masing. Selain itu perpustakaan mini juga dibuat di kelas. Buku-buku di perpustkaan mini ditata dan dijaga kerapiannya oleh guru dan semua siswa di kelas masing-masing. Buku akan digilir setiap seminggu sekali dengan tujuan siswa tidak bosan dengan bahan bacaan yang ada.

Ketiga, menata lingkungan yang kaya teks. Lingkungan yang kaya teks di SD N 3 Banjar Jawa bisa ditemukan di setiap sudut kelas, seperti ruang kelas, kantin, UKS, taman sekolah, dan kebun sekolah. Di ruang kelas di tempel slogan-slogan, foto presiden dan wakil presiden RI, serta foto-foto pahlawan. Selain itu, hasil kerajinan siswa dipajang di kelas. Dari hasil angket yang diberikan kepada masing-masing wali kelas, tujuan dari pemajangan hasil kerajinan tangan di kelas adalah: untuk menumbuhkan rasa bersaing siswa dalam berkreativitas, untuk menumbuhkan semangat siswa, mendorong siswa menyelesaikan pekerjaan dengan sungguh-sungguh, dan menumbuhkan rasa bangga siswa jika hasil kerajinannya dipajang.

Menata lingkungan yang kaya teks di kantin sekolah. Untuk mengkampanyekan makanan sehat, di kantin sekolah juga dipasang slogan dan poster. Poster yang dipasang di kantin sekolah misalnya "Pesan Keamanan Pangan oleh Badan POM RI dan Pilih Jajanan Sehat." Slogan yang dipasang adalah hasil karya siswa. di depan kantin juga diletakkan tempat mencuci tangan. Di dinding tempat mencuci tangan juga terdapat slogan dan poster yang mengkampanyekan cara mencuci tangan yang baik dan manfaat mencuci tangan.

Menata lingkungan yang kaya teks di UKS. UKS di SD N 3 Banjar Jawa terlihat sangat hijau dan bersih. Bahan kaya teks seperti slogan dan poster untuk mengkampanyekan gaya hidup sehat di tempel di dinding UKS dengan rapi. Slogan misalnya: "Cek Kesehatan secara Rutin, Enyahkan Asap Rokok, Rajin Aktivitas Fisik, Diet Seimbang, Istirahat Cukup, dan Kelola Stress (CERDIK)." Poster yang ditempel misalnya: "Ayo Lakukan Aktivitas Fisik Minimal 30 Menit Setiap Hari." Selain poster di UKS juga terdapat majalah dinding. Di mading ini terpasang kegiatan siswa saat mengikuti lomba PKTP (Penanggulangan Kanker Terpadu Paripurna) dan hasil karya siswa terkait kesehatan.

Selain itu, lingkungan yang kaya teks juga memanfaatkan kebun sekolah. Kebun sekolah dimanfaatkan untuk pemahaman siswa mengenai tanaman obat. Kebun SD N 3 Banjar jawa ditata dengan rapi dan bersih. Penataan kebun memanfaatkan barang bekas, seperti untuk pagar tanaman dibuat dari botol air mineral dengan plastik warna warni di dalamnya. Ada beberapa tanaman obat dan buah-buahan 
yang ditanamn di kebun ini. Tanaman obat dan buah diberikan label (nama tanaman, nama latin, dan manfaat). Untuk memberikan pengetahuan siswa tentang tanaman obat dan manfaatnya, di dinding depan UKS dipasangan poster besar memuat tentang jenis-jenis tanaman obat beserta manfaatnya.

Keempat, pojok baca dibeberapa area sekolah. Beberapa area sekolah pun disulap menjadi pojok baca. Salah satunya adalah aula. Tempat membaca di aula ini ditata sedemikian nyaman. Pojok baca juga diletakkan di lorong antara kelas V dan VI. Lorong ini sangat strategis untuk anak-anak membaca. Di lorong antara kelas V dan VI juga diletakkan rak kecil dengan beberapa buku cerita yang disusun rapi.

Kelima, kegiatan Sabtu Literasi. kegiatan ini dilakukan selama satu jam. Dari 90 siswa (tersebar dari kelas 4-6) yang diberikan kuisioner, 90 siswa atau 100\% siswa menyatakan suka dengan kegiatan 15 menit membaca dan Sabtu Literasi. Berdasarkan kegiatan-kegiatan dalam budaya literasi yang sudah dibuat SD N 3 Banjar Jawa dan dari hasil angket, persentase minat baca siswa SD N 3 Banjar Jawa mengalami peningkatan. Peningkatan persetase minat baca di kelas IV, V, dan VI dapat dilihat pada Tabel 1 di bawah ini.

Tabel 1. Data Persetase Peningkatan Minat Baca di Kelas IV, V, dan VI

\begin{tabular}{ccccc}
\hline l & Kelas & $\begin{array}{c}\text { Persetase Data } \\
\text { Minat Baca di Tahun } \\
\mathbf{2 0 1 6}\end{array}$ & $\begin{array}{c}\text { Persetase Data } \\
\text { Minat Baca di } \\
\text { Tahun 2017 }\end{array}$ \\
\hline$\vdots$ & IV A & $48 \%$ & $76 \%$ \\
& $\vdots$ & IV B & $45 \%$ & $72 \%$ \\
$\vdots$ & IV C & $43 \%$ & $74 \%$ \\
& V A & $48 \%$ & $78 \%$ \\
$\vdots$ & V B & $40 \%$ & $74 \%$ \\
& V C & $49 \%$ & $77 \%$ \\
& VI A & $50 \%$ & $63 \%$ \\
& VI B & $58 \%$ & $89 \%$ \\
\hline
\end{tabular}

Berdasarkan tabel di atas dapat disimpulkan bahwa dari 9 kelas yang terdiri dari kelas IV A, IV B, IV C, V A, V B, V C, VI A, VI B, dan VI A terjadi peningkatan minat baca sebesar $27 \%$. Ada beberapa kendala yang dihadapi selama pelaksanaan program budaya literasi di SD N 3 Banjar Jawa, yaitu sebagai berikut. Pertama, di awal pelaksanaan dirasa sulit mengarahkan anak untuk terbiasa membaca tanpa adanya perintah oleh wali kelas. Kedua, kendala yang paling berarti adalah kurangnya buku-buku cerita yang membuat pengetahuan tentang dunia, flora dan fauna, dan buku-buku cerita sains. Ketiga, sulitnya mengetahui kualitas membaca siswa saat kegiatan 15 menit membaca sebelum jam pelajaran begitu juga halnya pada saat Sabtu Literasi. Keempat, kurangnya tenaga pembersih kelas sehingga siswa yang mendapatkan giliran piket tidak bisa memanfaatkan waktu 15 menit untuk membaca.

Program budaya literasi di SD N 3 Banjar Jawa ini dibuat dengan berpedoman dari GLS (Gerakan Literasi Sekolah) yang diwajibkan oleh Kemendikbud. GLS adalah "kemampuan mengakses, memahami, dan menggunakan sesuatu secara cerdas melalui berbagai aktivitas, antara lain membaca, melihat, menyimak, menulis, dan/ atau berbicara (Direktorat Pembinaan Sekolah Dasar, 2016)." Tahapan pelaksanaan GLS di SD, yaitu: tahap pembiasaan, pengembangan, dan pembelajaran.

Sesuai dengan tahapan GLS, program budaya literasi yang dilakukan oleh SD N 3 Banjar Jawa baru pada tahap pembiasaan. Pada tahap pembiasaan usaha yang bisa dilakukan, yaitu sebagai berikut. Pertama, lima belas menit membaca sebelum jam pelajaran. Lima belas menit membaca sebelum jam pelajaran adalah program wajib Kemendikbud (Kemendikbud, 2015). Seperti yang dilakukan di SDN Gringging 1 Sambungmacan, Sragen bahwa kegiatan membaca 10-15 menit sebelum jam pelajaran adalah kegiatan yang paling menarik dan ramai terutama saat kegiatan menceritakan kembali apa yang dibaca (USAID/Indonesia, 2015). Dari hasil penelitian di SD kota Surabaya bahwa program membaca lima belas menit efektif meningkatakan keahlian membaca dan menulis serta memotivasi siswa membaca (Fijayanti, 2015). Hal yang sama juga dilakukan di SD N 3 Banjar Jawa. Kegiatan 15 menit membaca sebelum jam pelajaran ini tidak semata-mata dilakukan di kelas. Siswa boleh memilih tempat yang sudah disediakan sesuka hati. Siswa kadang memilih tempat di dekat taman, di depan kelas, di aula, atau di perpustakaan. Kemudian, setelah kegiatan ini siswa menceritakan kembali apa yang dibaca secara lisan dan tulisan serta mendiskusikan nilai-nilai yang terdapat dalam cerita. Kegiatan inilah yang paling disukai oleh siswa dan siswa termotivasi untuk terus membaca. 
Kedua, menata perpustakan sekolah dan perpustakaan mini di kelas. Salah satu upaya yang dapat dilakukan kepala sekolah untuk meningkatkan motivasi siswa membaca adalah dengan menata perpustakaan sekolah dengan baik, nyaman, dan teratur serta menambah koleksi buku dan bahan perpustakaan lainnya (Irawati, 2014). Terkait hal ini, untuk suksesnya budaya literasi di SD N 3 Banjar Jawa, kepala sekolah dan guru-guru merasa sangat perlu membenahi perpustakaan agar menjadi tempat yang nyaman untuk siswa-siswinya membaca dan belajar. Buku-buku ditambah dengan mengalokasikan dana BOS $5 \%$ untuk pembelian buku. Sumbangan buku secara personal dan kolektif juga diterima oleh pihak sekolah. Tempat duduk dibuat lesehan agar siswa merasa nyaman membaca. Poster dan slogan untuk menggairahkan siswa membaca juga banyak ditempel di dinding perpustakaan. Selain itu, untuk memudahkan siswa membaca, di kelas juga dibuat perpustakaan mini. Buku di perpustakaan ini digilir setiap satu bulan sekali. Siswa bersama-sama menjaga kerapian buku. Siswa merasa sangat senang jika ada buku baru yang ditambah di perpustakaan ini.

Ketiga, menata lingkungan yang kaya teks. Menurut Lipton dan Hubble, "siswa perlu dilibatkan dalam lingkungan yang kaya akan materi tercetak yang terkait dengan-dan bersumber dari-pengalaman mereka (Lipton \& Hubble, 2016)." Di SD N 3 banjar Jawa, slogan-slogan dan hasil kerajinan tangan yang dibuat oleh siswa dipajang di kelas, aula, kantin, uks, perpustakaan, dan taman. Siswa merasa sangat senang jika hasil tangan mereka dipajang dan mereka semakin termotivasi untuk berkarya yang lebih bagus lagi.

Hal ini terkait dengan kajian dengan judul "Menggagas Kajian Kearifan Budaya Lokal di Sekolah Dasar Melalui Gerakan Literasi Sekolah" bahwa pada tahap pembiasaaan, hal pertama yang harus dilakukan adalah "menyediakan perpustakaan sekolah, sudut baca, area baca yang nyaman, serta bahan baca yang baik cetak maupun digital yang dapat diakses peserta didik ataupun warga sekolah lainnya". Selain itu, hal yang perlu disiapkan, seperti UKS yang harus mengkampanyekan cara hidup sehat, kantin yang bersih, sehat, dan menjual makanan yang sehat, serta kebun sekolah yang menyediakan laboratorium hidup untuk pemahaman siswa tentang manfaat tanaman obat (Oktaviani, Zuliana, \& Ratnasari, 2017). Hal ini sudah dilaksanakan oleh SD N 3 Banjar Jawa. UKS SD N 3 Banjar dengan membuat lingkungan yang kaya akan teks, seperti slogan dan poster untuk mengkampanyekan gaya hidup sehat di tempel di dinding UKS dengan rapi. Slogan misalnya: "Cek Kesehatan secara Rutin, Enyahkan Asap Rokok, Rajin Aktivitas Fisik, Diet Seimbang, Istirahat Cukup, dan Kelola Stress (CERDIK)." Poster yang ditempel misalnya: "Ayo Lakukan Aktivitas Fisik Minimal 30 Menit Setiap Hari."

Selain UKS, di kantin SD N 3 Banjar Jawa menjual makanan yang sehat. Kepala Sekolah yakin bahwa makanan yang tidak sehat dapat menghambat siswa untuk maju dan berprestasi. Untuk mengkampanyekan makanan sehat, di kantin sekolah juga dipasang slogan dan poster. Slogan yang dipasang di kantin sekolah misalnya: "Makanan Sehat Membuat Tubuh Bugar dan Pilih Makanan dengan Bijak agar Hidup Sehat." Poster yang dipasang di kantin sekolah misalnya "Pesan Keamanan Pangan oleh Badan POM RI dan Pilih Jajanan Sehat."

Keempat, pojok baca. Dari hasil penelitian mengenai "Implementasi Gemar Membaca Melalui Program Pojok Baca dalam Mata Pelajaran IPS pada Siswa Kelas VIII di SMPN 2 Sumber", pojok baca di SMPN 2 Sumber dibuat sudut masing-masing kelas, taman baca di samping perpustakaan dan di depan ruang guru, dan lorong baca kelas yang diadakan pada bulan maret 2016 (Nugroho, Puspitasari, \& Puspitasari, 2016). Di SD N 3 Banjar Jawa, beberapa area sekolah disulap menjadi pojok baca. Salah satunya adalah aula. Tempat membaca di aula ini ditata sedemikian nyaman. Untuk memudahkan anakanak membaca, di aula ini juga diletakkan rak buku yang dibuat menarik. Setiap rak berisi slogan-slogan seperti "BUDAYAKAN MEMBACA SEJAK DINI, DENGAN MEMBACA KITA TAHU ISI DUNIA" dengan tujuan siswa semakin sadar akan pentingnya membaca bagi kehidupannya. Pojok baca juga diletakkan di lorong antara kelas V dan VI. Lorong ini sangat strategis untuk anak-anak membaca. Di lorong antara kelas V dan VI juga diletakkan rak kecil dengan beberapa buku cerita yang disusun rapi.

Kelima, kegiatan Sabtu Literasi. Kegiatan ini dilakukan selama satu jam. Setengah jam dilakukan untuk kegiatan membaca, setengah jam lagi untuk kegiatan menceritakan kembali isi cerita secara lisan dan tulisan. Selain itu, setelah membaca siswa dan guru mendiskusikan tema, tokoh, latar, dan amanat dalam cerita. Kegiatan ini dilakukan di kelas dan dipandu oleh wali kelas. Siswa diarahkan untuk membaca secara mandiri dan buku diambil dari perpustakan mini yang ada di kelas. Siswa merasa sangat senang dengan kegiatan ini.

Perhatian kepala sekolah SD N 3 Banjar Jawa untuk meningkatkan minat baca siswa melalui program budaya literasi ini membawa dampak yang baik, terutama meningkatnya keinginan siswa untuk membaca. Program budaya literasi yang berpedoman pada gerakan Literasi Sekolah (GLS) juga berdampak positif, yaitu menjadi rajin membaca. Dengan kata lain, minat baca siswa meningkat dengan adanya kegiatan GLS (Faradina, 2016). Begitu pula dari hasil observasi di SD N 3 Banjar Jawa, siswa sudah mulai gemar membaca di jam-jam istirahat. Dari hasil sabtu literasi, keberanian anak-anak 
menyampaikan kembali dari apa yang dibaca juga sangat baik. Siswa mampu menyampaikan kembali apa yang dibaca di depan teman-temannya dengan bahasa sendiri dan sangat lancar.

Ada beberapa dampak postif bagi siswa dengan adanya program budaya literasi, yaitu: siswa menjadi terbiasa membaca; membangkitkan rasa percaya diri siswa; siswa termotivasi untuk membaca; siswa mengenal bermacam-macam cerita; menambah wawasan siswa; menumbuhkan minat membaca siswa; siswa lebih termotivasi untuk mengembangkan kemampuan berceritanya; siswa lebih mudah untuk menyampaikan isi wacana; siswa memeroleh informasi baru yang selama ini belum diketahui; siswa memiliki budaya membaca dan menulis. Selain itu, dari hasil angket minat baca siswa mengalami peningkatan dari 48\% di tahun 2016 menjadi 75\% di tahun 2107.

Ada beberapa solusi yang bisa ditawarkan untuk mengatasi kendala yang dihadapi selama pelaksanaan program budaya literasi di SD N 3 Banjar Jawa, yaitu sebagai berikut. Pertama, memberikan motivasi untuk gemar membaca dan pentingnya membaca yang diserukan setiap hari senin pada saat upacara bendera. Motivasi juga diberikan saat proses pembelajaran di kelas dan pada saat kegiatan Sabtu Literasi. Kedua, untuk masalah kurangnya buku cerita, kepala sekolah telah menganggarkan $5 \%$ dana bos untuk buku perpustakaan. Buku juga diperoleh dari sumbangan orang tua atau dari keiklasan siswa membawa buku cerita sendiri ke sekolah. Kepala sekolah juga berusaha dan sangat menyambut sumbangan buku dari semua pihak, misalnya kampus, yayasan yang peduli terhadap pendidikan, atau pemerintah khsusnya perpustakaan daerah. Ketiga, perlu diawasi kualitas membaca siswa dengan memaksimalkan lagi tugas dari masing-masing wali kelas. Keempat, pihak sekolah akan mengusahakan agar ada jasa pembersih di masing-masing kelas.

\section{KESIMPULAN}

Dari pembahasan di atas program budaya literasi sangat penting dilakukan di sekolah dasar. Program budaya literasi yang dikerjakan serius, berkelanjutan, dan didukung oleh semua warga sekolah akan mampu meningkatkan minat baca siswa. Membiasakan membaca sejak dini akan menghasilkan budaya. Jika sudah menjadi budaya, maka SDM bangsa Indonesia akan meningkat. SDM meningkat, bangsa Indonesia juga akan semakin maju

\section{DAFTAR PUSTAKA}

Direktorat Pembinaan Sekolah Dasar. (2016). Panduan Gerakan Literasi Sekolah di Sekolah Dasar. (P. Wiedarti \& K. Laksono, Eds.). Jakarta: Direktorat Pembinaan Sekolah Dasar. Retrieved from http://repositori.perpustakaan.kemdikbud.go.id/40/1/Panduan-Gerakan-Literasi-Sekolah-diSD.pdf

Faradina, N. (2016). Peningkatan Minat Baca Siswa Sekolah Dasar Melalui kegiatan GLS (Gerakan Literasi Sekolah) di Dinas Pendidikan Kabupaten Klaten. Yogyakarta. Retrieved from http://eprints.uny.ac.id/50401/1/Nindya Faradina 13101241039.pdf

Fijayanti, I. (2015). Program Membaca Lima Belas Menit (Sustained Silent Reading) Pada Siswa dan Siswi Sekolah Dasar Negeri di Kota Surabaya. Libri-Net, 4(3), 526-544. Retrieved from http://journal.unair.ac.id/LN@program-membaca-lima-belas-menit-(sustained-silent-reading)article-9216-media-136-category-8.html.

Irawati. (2014). Upaya Kepala Sekolah dalam Meningkatkan Pengelolaan Perpustakaan di Sekolah Dasar. Administrasi Pendidikan, 2(1), 335-340. Retrieved from http://ejournal.unp.ac.id/index.php/bahana/article/viewFile/3771/3005

Kemendikbud. (2015). Peraturan Menteri Pendidikan dan Kebudayaan Republik Indonesia Nomor 23 Tahun 2015 tentang Penumbuhan Budi Pekerti. Retrieved from http://dikdas.kemdikbud.go.id/wpcontent/uploads/2015/10/Permendikbud-No-23-Tahun-2015.pdf

Kompas. (2016, August 29). Minat Baca Indonesia Ada di Urutan ke-60 Dunia. Retrieved from http://edukasi.kompas.com/read/2016/08/29/07175131/minat.baca.indonesia.ada.di.urutan.ke60.dunia

Lipton, L., \& Hubble, D. (2016). Sekolah Literasi: Perencanaan dan Pembinaan. Bandung: Nuansa.

Moleong, L. J. (2013). Metodologi Penelitian Kualitatif. Bandung: PT Remaja Rosdakarya. 
Nugroho, A., Puspitasari, R., \& Puspitasari, E. (2016). Jurnal Edueksos Volume V No 2, Desember 2016187. Edueksos, $\quad V(2), \quad 187-206 . \quad$ Retrieved from http://download.portalgaruda.org/article.php?article=471297\&val=9452\&title=IMPLEMENTASI GEMAR MEMBACA MELALUI PROGRAM POJOK BACA DALAM MATA PELAJARAN IPS PADA SISWA KELAS VIII DI SMPN 2 SUMBER.

Oktaviani, I., Zuliana, E., \& Ratnasari, Y. (2017). Menggagas Kajian Kearifan Budaya Lokal di Sekolah Dasar Melalui Gerakan Literasi Sekolah. In Aktualisasi Kurikulum 2013 dIi Sekolah Dasar Melalui Gerakan Literasi Sekolah untuk Menyiapkan Generasi Unggul dan Berbudi Pekerti (pp. 35-42). Retrieved from https://www.researchgate.net/publication/318760691_MENGGAGAS_KAJIAN_KEARIFAN_BUDAYA _LOKAL_DI_SEKOLAH_DASAR_MELALUI_GERAKAN_LITERASI_SEKOLAH

Rahim, F. (2011). Pengajaran Membaca di Sekolah Dasar. Jakarta: Bumi Aksara.

Rahma, N. M., Pratiwi, R. N., \& Lastiti, N. V. . (2015). ( Studi pada Ruang Baca Anak Perpustakaan Umum dan Arsip Daerah Kota Malang ). Administrasi Publik (JAP), 3(5), 763-769. Retrieved from https://media.neliti.com/media/publications/81738-ID-strategi-peningkatan-minat-baca-anakstu.pdf

Sudiana, I. N. (2007). Membaca. Malang: UM Press.

USAID/Indonesia. (2015). Praktik yang Baik Budaya Baca dI SD/MI DAN SMP/MTs. Jakarta: Direktur Jenderal Pendidikan Dasar. Retrieved from http://pdf.usaid.gov/pdf_docs/PA00M3T4.pdf. 